\title{
LA ESCUELA COMO ESPACIO DE APRENDIZAJE DE IDENTIDADES \\ CIUDADANAS MODERNAS \\ E INTERCULTURALES: ser limeños, ser señoritas, ser japones $^{1}$
}

\author{
Mercedes Giesecke S. L.
}

\begin{abstract}
Sumilla
¿Cuáles son las aspiraciones de los padres al colocar a sus hijos e hijas en determinada escuela? Tal vez esperan un determinado tipo de socialización útil para el desempeño posterior de sus hijas e hijos como adultos. En esta ponencia haré un análisis inicial tanto de las entrevistas a varios alumnos y alumnas de cinco distintos colegios de Lima, como de los Proyectos Educativos Institucionales (PEI) de cada uno de estos colegios. El objetivo es comprender si los colegios elegidos por los padres para que sus hijos e hijas estudien allí, se debe por la importancia dada a los valores que promueve la escuela. Así mismo, busco reconocer desde la mirada de los propios
\end{abstract}

\footnotetext{
Esta ponencia se inspira en los datos y análisis hecho por los ayudantes de cátedra y de los alumnos del curso de Introducción a la Antropología bajo mi asesoría, en el segundo semestre de Antropología en San Marcos. Los ayudantes de cátedra fueron Dynnik Asencio, Catalina Durand, Jessica Aguilar, Josué Gonzales y Rocío Ley. Se realizaron un conjunto de entrevistas gracias al interés y apoyo de los directores de cinco colegios: Teresa González de Fanning (Jesús María), La Victoria (La Victoria), José María Arguedas (San Juan de Miraflores), Elías Aguirre-Casa Abierta (Villa el Salvador), Héroes de la Breña (San Juan de Lurigancho), también gracias al interés de los mismos y de las mismas escolares, quienes espontáneamente se ofrecieron a dar sus entrevistas. Para hacer este trabajo los alumnos y las alumnas del curso de San Marcos también se nutrieron, en la parte práctica, de la discusión de las siguientes lecturas: Memoria del bien perdido, Consideraciones sobre interculturalidad y educación, Diana Vallescar, CVR, T. IX: Recomendaciones de la CVR: hacia un compromiso nacional de reconciliación: Parte I: reconciliación: propuesta. Parte II: reconciliación, límites y perspectivas. Conclusiones; Democracia y participación indígena: el caso peruano Sinesio López. Antropología de Conrad Phillip Kottak fue lectura de teoría.
} 
alumnos y alumnas entrevistadas, qué es lo que ellos y ellas valoran y, por último, saber lo que el propio director propone a través del PEI. En conclusión, se trata de analizar el diálogo que se produce desde los diversos actores mencionados, desde sus historias socioculturales y desde sus aspiraciones culturales; saben que necesitan de la escuela como estrategia intercultural para el aprendizaje de nuevos códigos para la propia modernización de sus identidades limeñas, de señoritas y de japoneses, para así alcanzar una ciudadanía más solvente.

La configuración de la ciudadanía actual y futura tiene mucho que ver con la forma en que se insertó la colonia en la tierra americana y en el mundo entero. Época en la que dominó el criterio aristotélico estamental —esa rígida jerarquización de los estamentos raciales - que justificó la exclusión y explotación de aquellos colocados en la periferia del dominio colonial.

Esta situación promocionó un profundo afán de negación del otro andino, generándose en un primer momento movimientos milenaristas, pero cediendo con el paso de los siglos a una nueva redefinición identitaria en la conocida fórmula del mestizaje.

Para el indígena, que no era noble, era fundamental huir de su condición de indio para evitar ser llevado a la mita en las minas, obrajes y otros trabajos forzados, y para el español pobre era importante casarse con una india de la nobleza inca. En términos generales se produjeron muchos matrimonios "mixtos", unos reconocidos legalmente y otros solo como convivientes —aunque en su mayoría debían formalizar sus relaciones ${ }^{2}$ -

Este mestizaje no logró superar los problemas de explotación económica y cultural, por tal motivo la presencia de movimientos indígenas fue algo recurrente. El enfoque de este mestizaje fue y aún pervive como la negación al otro andino.

Con la independencia, aunque se dio el paso de súbditos a ciudadanos, el y la ciudadana como tal tuvieron que ser poseedores de un conjunto de requisitos formales y materiales para ejercer de hecho su participación en las decisiones o para hacer respetar sus derechos. Con la independencia aparecieron nuevas situaciones mercantiles, políticas, laborales, culturales, entre otras. Las relaciones asalariadas en los enclaves que se crearon van a cambiar el viejo modelo servil, pero en menor medida aún. Aparece el tema de la libertad de los esclavos. Los problemas socioculturales se complejizaron con la llegada de los asiáticos y europeos.

En el siglo xx, aparece la necesidad de forjar la inclusión de las mayorías a un Estado-nación único, se toma la decisión de ampliar la ciudadanía utilizando la escolarización como medio. La ciudadanía que surge de este hecho tiene un sesgo cultural similar al de la colonia, mejor dicho es una actualización de ese mestizaje arraigado

\footnotetext{
2 Además, como es sabido, hubieron muchas clases de cruces raciales.
} 
en la noción de la negación del otro andino, para lograr su participación en la civilización moderna que ofrecían los Estados-nación de la época.

A partir de los años 20, las nuevas élites modernizantes vinculadas al Leguiismo, los nuevos sectores intelectuales y los movimientos indigenistas contribuyeron a que el Estado se declarara protector de la raza indígena, impulsara el reconocimiento formal de su cultura, reconociera su organización comunal, pero la excluyera de la participación política al exigir a los votantes el estatus de contribuyentes, la condición de alfabetos y de hombres mayores de 21 años. Esta apertura del Estado a algunos derechos civiles de los campesinos indígenas es lo que se ha dado en llamar ciudadanía tutelada. Con el mismo sentido se estableció el papel mediador del Estado en el conflicto entre los patrones y trabajadores (López 1997: 234-5).

Esta ciudadanía tutelada, significa que no bastaron las "estrategias políticas para construir la ciudadanía” (Ibíd: 219), fue necesario incluir "estrategias específicamente culturales que han permitido ciertos acercamientos y el establecimiento de algunas políticas de reconocimiento" (Ibíd). Una de estas fue la estrategia cultural educativa a través de la cual se dio un acriollamiento forzado impulsado por el civilismo entre 1900 y 1930; luego se dio un acriollamiento amable impulsado por el indigenismo en los años 40. Por otro lado se dio la cholificación como estrategia impulsada por la propia población andina a partir de los años 50, a través de la "migración a las ciudades, la inserción en el mercado, el abandono del quechua y de la vestimenta. De la mantención de los valores culturales indígenas y asumiendo los valores occidentales en una nueva identidad" (Ibíd). Con Velasco se desarrolló una política de reconocimiento hacia el mundo indígena pero en términos generales no modificó las estrategias previas monoculturales. No se logró construir una comunidad política nacional.

La escolarización para la integración nacional debía transmitir los códigos de esta primera modernidad, tales como el idioma castellano, la ropa, ciertos hábitos y costumbres. Esta escolarización fue un medio masivo de transformación cultural con énfasis en la "modernización” del indio, es decir su integración monocultural como forma de negación de su ser indio.

Aquí se produce un nuevo proceso de mestizaje que implica un nuevo espacio de encuentro, donde el "indio" se descubre a sí mismo como actor social. Se da una reinterpretación de la escuela hacia la satisfacción de una demanda fundamental, saber castellano y dominar la comunicación para lograr el éxito cultural. Aquí se niega el Yo quechua o vernácula y emerge un Yo cholo culturalmente exitoso, identidad vinculante entre el mundo rural y el urbano, y la nación como totalidad, ya que la identidad nacional se fundamentó entre otras cosas en el idioma castellano “... la castellanización y la educación constituían los mecanismos culturales de una homogenización forzada; independientemente de si los indígenas asistían de buena o mala gana a la escuela" (Ibíd: 220). 
... sectores del estrato indígena y campesino, que al pasar por el "tamiz" de la educación secundaria comenzaron a ser considerados "mestizos" en términos culturales [...] significando sus estudios el fruto de un sacrificado desarraigo personal y económico de sus familias (Contreras 1996: 26).

En el siglo xx, con la globalización, se ha planteado una segunda modernidad como fracaso de la primera ${ }^{3}$. Hoy se cuestiona mucho más enfáticamente la exclusión y la negación cultural de los pueblos subordinados por los procesos coloniales; también el hecho de que la primera modernidad no ha resuelto los problemas fundamentales de pobreza sino que ha creado más problemas socioculturales, económicos, políticos entre otros. Hoy nace el enfoque de una ciudadanía intercultural, que es otro enfoque para reflexionar el mestizaje, cuyo principio es el reconocimiento de las diversas culturas, con el ejercicio libre y pleno de una ciudadanía individual y sociocultural, culturalmente diferenciada, socialmente respetada y políticamente expresada. Esta ciudadanía intercultural asume el sincretismo como dimensión adaptante entre culturas. Proporciona una teoría, un sentimiento y una práctica orientada a una praxis que busca en primera instancia revertir la automarginación y la negación del otro andino, para lograr una autoestima identitaria andina totalmente revalorada.

En esta segunda modernidad tres son los pilares que deben contribuir a su configuración: la ciudadanía intercultural, los medios de comunicación y la escuela ${ }^{4}$.

En esta segunda parte de la ponencia me interesa mirar de cerca la realidad elegida para conocer en un primer momento la situación vivida desde la mirada institucional y desde la mirada de los propios alumnos. Para poder reconocer mejor los ángulos en los que se expresa el conflicto cultural.

Los Proyectos Educativos Institucionales parecen haberse constituido en una herramienta de desarrollo institucional, los que duran varios años y son complementados por planes anuales. El colegio privado La Victoria y el colegio Elías Aguirre tenían al día sus respectivos $\mathrm{PEI}^{5}$, los otros colegios los tenían en proceso de elaboración.

El cuestionamiento más importante es ver de qué manera se ven reflejadas dos dimensiones de la realidad en los datos expuestos: por un lado las identidades locales de las familias cuyos hijos asisten a estos colegios y por el otro, la identidad escolar nacional, forjada desde la óptica monoculturalista de negación al otro andino para lograr su "modernización".

\footnotetext{
3 Ver BECK Ulrich en la bibliografía final.

Ver CALDERÓN et al. en la bibliografía final.

No pudimos acceder al PEI del colegio Teresa González de Fanning, según informaron estaba en proceso de elaboración, se recibieron datos mediante entrevistas.
} 


\section{Cuadro 1}

Fundación, ubicación y poblaciones atendidas ${ }^{6}$

\begin{tabular}{|c|c|c|c|c|c|}
\hline $\begin{array}{l}\text { Colegio: } \\
\text { datos }\end{array}$ & $\begin{array}{c}\text { Héroes de la } \\
\text { Breña }\end{array}$ & $\begin{array}{c}\text { José María } \\
\text { Arguedas }\end{array}$ & $\begin{array}{c}\text { Elías Aguirre } \\
\text { y Casa } \\
\text { Abierta }\end{array}$ & $\begin{array}{c}\text { Teresa } \\
\text { González de } \\
\text { Fanning }\end{array}$ & La Victoria \\
\hline $\begin{array}{l}\text { Fecha de } \\
\text { fundación }\end{array}$ & 1987 & 1983 & 1992 & 1952 & 1948 \\
\hline $\begin{array}{l}\mathrm{N}^{\circ} \text { del } \\
\text { C.E. }\end{array}$ & $\begin{array}{l}\mathrm{N}^{\circ} 150 \\
\text { Ugel } 05\end{array}$ & $\begin{array}{l}\mathrm{N}^{\circ} 7081 \\
\text { Ugel } 01\end{array}$ & $N^{\circ} 7224$ & & Privado \\
\hline Ubicación & $\begin{array}{l}\text { San Juan de } \\
\text { Lurigancho } \\
\text { Huanta I }\end{array}$ & $\begin{array}{l}\text { San Juan de } \\
\text { Miraflores }\end{array}$ & $\begin{array}{l}\text { Villa el Salva- } \\
\text { dor- IV Etapa }\end{array}$ & Jesús María & $\begin{array}{l}\text { La Victoria } \\
\text { zona comer- } \\
\text { cial }\end{array}$ \\
\hline $\begin{array}{l}\text { Población } \\
\text { atendida }\end{array}$ & $\begin{array}{l}\text { AAHH Juan } \\
\text { Pablo II, } \\
\text { Las Lomas, } \\
\text { Miguel Grau, } \\
\text { Sagrada } \\
\text { Familia, San } \\
\text { Juan Bautista, } \\
\text { San Pablo, } 21 \\
\text { de septiembre, } \\
8 \text { de octubre y } \\
\text { El Dorado. }\end{array}$ & $\begin{array}{l}\text { AAHH } \\
\text { Susana } \\
\text { Higuchi y } \\
\text { otros. }\end{array}$ & $\begin{array}{l}\text { Barrio } 2 \text { y } 4, \\
\text { AAHH Max } \\
\text { Uhle, Las } \\
\text { Brisas, Los } \\
\text { Aires de Pach, } \\
\text { Virgen de la } \\
\text { Candelaria, } \\
\text { Los Portales. }\end{array}$ & $\begin{array}{l}\text { Atiende } \\
\text { alumnas que } \\
\text { vienen a } \\
\text { estudiar de } \\
\text { todo Lima y } \\
\text { provincias. }\end{array}$ & $\begin{array}{l}\text { La Victoria, } \\
\text { reinmigran- } \\
\text { tes del Japón } \\
\text { y quienes } \\
\text { piensan ir } \\
\text { por primera } \\
\text { vez al Japón. }\end{array}$ \\
\hline
\end{tabular}

Los colegios más antiguos se caracterizan por estar ubicados en zonas tradicionales de la ciudad, y los colegios más recientes conformados entre los años 1983 a 1992 y están ubicados en asentamientos humanos.

El $40 \%$ del alumnado proveniente del colegio Héroes de la Breña ha migrado de Huanta a causa de la violencia en la época del terrorismo. 


\section{Cuadro $2^{7}$}

\begin{tabular}{|c|c|c|c|c|c|}
\hline $\begin{array}{l}\text { Tipo de } \\
\text { construc- } \\
\text { ción }\end{array}$ & $\begin{array}{l}\text { Autoconstruc- } \\
\text { ción con apoyo } \\
\text { estatal y de } \\
\text { los padres. Es } \\
\text { material noble } \\
\text { la mayor parte. }\end{array}$ & $\begin{array}{l}\text { Autoconstruc- } \\
\text { ción. En sus } \\
20 \text { años pasó } \\
\text { de } 2 \text { aulas a } \\
16 \text { de material } \\
\text { noble. }\end{array}$ & $\begin{array}{l}\text { Autocons- } \\
\text { trucción es } \\
\text { de material } \\
\text { noble. }\end{array}$ & $\begin{array}{l}\text { Estatal una } \\
\text { parte antigua } \\
\text { y una parte } \\
\text { nueva cons- } \\
\text { truida por el } \\
\text { gobierno. }\end{array}$ & $\begin{array}{l}\text { Adquirido } \\
\text { con el } \\
\text { apoyo de la } \\
\text { comunidad } \\
\text { educativa. }\end{array}$ \\
\hline
\end{tabular}

Los colegios de creación más reciente incluyen en su identidad la odisea realizada para lograr, a través de la autoconstrucción y apoyo de varias instituciones, levantar con material noble estos colegios, que aún están buscando la manera de completar los ambientes necesarios para cubrir el conjunto de sus necesidades. El Teresa González de Fanning y La Victoria parecen haber logradocubrir todas sus necesidades.

\section{Cuadro 3}

\begin{tabular}{|c|c|c|c|c|c|}
\hline $\begin{array}{l}\text { Colegio: } \\
\text { datos }\end{array}$ & $\begin{array}{c}\text { Héroes de } \\
\text { la Breña }\end{array}$ & $\begin{array}{c}\text { José María } \\
\text { Arguedas }\end{array}$ & $\begin{array}{c}\text { Elías } \\
\text { Aguirre y } \\
\text { Casa Abierta }\end{array}$ & $\begin{array}{c}\text { Teresa } \\
\text { González de } \\
\text { Fanning }\end{array}$ & $\begin{array}{c}\text { La } \\
\text { Victoria }\end{array}$ \\
\hline Coeducación & mixto & mixto & mixto & femenino & mixto \\
\hline Turnos & $\begin{array}{c}\text { mañana y } \\
\text { tarde }\end{array}$ & $\begin{array}{c}\text { mañana y } \\
\text { tarde }\end{array}$ & $\begin{array}{c}\text { mañana y } \\
\text { tarde }\end{array}$ & $\begin{array}{c}\text { mañana, } \\
\text { tarde, noche } \\
\text { para adultos }\end{array}$ & día \\
\hline
\end{tabular}

Se puede corroborar la demanda educativa porque todos lo colegios tienen cubiertas sus plazas de alumnado, salvo el caso de La Victoria en el cual los y las alumnas parten para Japón con sus familiares. Se resalta la presencia del TGF como colegio femenino.

7 La autoconstrucción con apoyo estatal y de los padres es una cruzada para conseguir los materiales de contrucción a través de la donación de mobiliarios en desuso de otros centros educativos de Lima; la "marcha de los ladrillos" organizada por los profesores y alumnos para conseguir ladrillos de los padres de familia; la recaudación de fondos a través de actividades; el apoyo del Ministerio de Educación con bolsas de cemento, el apoyo de Foncodes con dinero y la realización de aulas por el INFES. Así, el conjunto de acciones realizadas a través de la autoconstrucción de la Institución Escolar, desde 1987 año en el cual se contaba con un solo profesor y un aula multigrados de estera, hasta 1997 en que el colegio ha crecido enormemente. 
Cuadro $4^{8}$

\begin{tabular}{|c|c|c|c|c|c|}
\hline $\begin{array}{l}\text { Colegio: } \\
\text { datos }\end{array}$ & $\begin{array}{c}\text { Héroes de } \\
\text { la Breña }\end{array}$ & $\begin{array}{l}\text { José María } \\
\text { Arguedas }\end{array}$ & $\begin{array}{c}\text { Elías Aguirre y } \\
\text { Casa Abierta }\end{array}$ & $\begin{array}{c}\text { Teresa } \\
\text { González de } \\
\text { Fanning }\end{array}$ & La Victoria \\
\hline $\begin{array}{l}\mathrm{N}^{\circ} \text { de } \\
\text { alumnado }\end{array}$ & $\begin{array}{l}\text { ¿más de } \\
\text { mil? }\end{array}$ & 1300 & 1757 & 6200 & 210 \\
\hline $\begin{array}{l}\mathrm{N}^{\circ} \text { de } \\
\text { docentes }\end{array}$ & ¿45? & 47 & 56 & 315 & $\begin{array}{l}20 \text { cursos } \\
\text { regulares y } \\
10 \text { cursos } \\
\text { especiales }\end{array}$ \\
\hline $\begin{array}{l}\text { Alumnos/ } \\
\text { docentes }\end{array}$ & & $\begin{array}{l}27.6 \text { alum- } \\
\text { nos/docente }\end{array}$ & $\begin{array}{l}31.4 \text { alumnos / } \\
\text { docente }\end{array}$ & $\begin{array}{l}33.2 \text { alumno/ } \\
\text { docente }\end{array}$ & $\begin{array}{c}10 \text { alumno/ } \\
\text { docente }\end{array}$ \\
\hline $\begin{array}{l}\mathrm{N}^{\circ} \text { de } \\
\text { Auxiliares }\end{array}$ & ¿? & ¿? & 3 & 51 & $\begin{array}{l}1 \text { psicóloga, } \\
4 \text { secretarias, } \\
1 \text { auxiliar de } \\
\text { educación, } 1 \\
\text { persona de } \\
\text { limpieza }\end{array}$ \\
\hline $\mathrm{N}^{\circ}$ aulas & ¿? & ¿? & 22 & 185 & 12 \\
\hline Ambiente & ¿? & $\begin{array}{l}\text { Biblioteca, } \\
\text { laboratorio } \\
\text { de biología } \\
\text { y química, } \\
\text { dos salas de } \\
\text { cómputo, } \\
\text { un taller de } \\
\text { carpintería } \\
\text { y otro de } \\
\text { zapatería. }\end{array}$ & $\begin{array}{l}\text { Biblioteca, } \\
\text { servicios } \\
\text { higiénicos, loza } \\
\text { deportiva, mini } \\
\text { fútbol, cerco } \\
\text { perimétrico. }\end{array}$ & $\begin{array}{l}\text { Equipo y } \\
\text { mobiliarios } \\
\text { adecuados, } \\
\text { laboratorios, } \\
\text { bibliotecas, } \\
\text { gimnasio, áreas } \\
\text { deportivas, sala } \\
\text { de cómputo, } \\
\text { talleres y capilla. } \\
\text { SSHH. }\end{array}$ & $\begin{array}{l}32 \text { ambien- } \\
\text { tes además } \\
\text { de las aulas. }\end{array}$ \\
\hline
\end{tabular}

En el colegio La Victoria los profesores para cursos especiales son 4 para Idioma japonés, 1 de Folklore-arte, Música folklórica, Computación, Ballet, Karate, Cocina y Repostería.

En el colegio Elías Aguirre y Casa Abierta faltan ambientes administrativos, biblioteca, laboratorios, sala de profesores, sala de estudio de matemática, de cómputo, dep. educación física y departamento de OBE.

En el colegio La Victoria entre los ambientes encontramos dirección, Apafa, secretaría técnico-pedagógica, 2 laboratorios, administración, departamento de idioma japonés, psicología, educación física, audiovisuales, música, profesores, cómputo, terapia recuperativa, juegos, atención a padres de familia, biblioteca, 2 kioskos, talleres, SSHH, depósito. 
En los colegios nacionales hay una importancia enorme dada a los auxiliares, especie de policías de disciplina al interior de los colegios. Hay un promedio de 30 alumnos por profesor. Los colegios que tienen menor infraestructura están en los asentamientos humanos, uno de los elementos importantes es la seguridad que les da el cerco perimétrico del colegio, en cuanto a su aislamiento al pandillaje.

Cuadro $5^{9}$

\begin{tabular}{|c|c|c|c|c|c|}
\hline $\begin{array}{l}\text { Colegio: } \\
\text { dato }\end{array}$ & $\begin{array}{c}\text { Héroes } \\
\text { de la Breña }\end{array}$ & $\begin{array}{l}\text { José María } \\
\text { Arguedas }\end{array}$ & $\begin{array}{c}\text { Elías Aguirre y } \\
\text { Casa Abierta }\end{array}$ & $\begin{array}{c}\text { Teresa } \\
\text { González de } \\
\text { Fanning }\end{array}$ & La Victoria \\
\hline $\begin{array}{l}\text { Presencia del } \\
\text { Ministerio de } \\
\text { Educación }\end{array}$ & ¿? & $\begin{array}{l}\text { Reconocido } \\
\text { como } \\
\text { colegio } \\
\text { piloto, } \\
\text { cuenta con } \\
\text { profesores } \\
\text { de Plancad. }\end{array}$ & $\begin{array}{l}\text { Apoyo de la } \\
\text { USE con psi- } \\
\text { cólogos para } \\
\text { prevenir el al- } \\
\text { coholismo. Año } \\
2001 \text { se llevó el } \\
\text { plan Huascarán. }\end{array}$ & $\begin{array}{l}\text { Proyectos } \\
\text { Edured, } \\
\text { Globe, Kidlink } \\
\text { y Huascarán }\end{array}$ & $\begin{array}{l}\text { Institución } \\
\text { educativa } \\
\text { sujeta a } \\
\text { la Ley } \\
\text { General de } \\
\text { Educación }\end{array}$ \\
\hline $\begin{array}{l}\text { Fuente de } \\
\text { financiamiento }\end{array}$ & $\begin{array}{l}\text { Apoyo } \\
\text { estatal } \\
\text { para cons- } \\
\text { trucción, } \\
\text { desayunos } \\
\text { escolares. }\end{array}$ & ¿? & $\begin{array}{l}\text { Donaciones de } \\
\text { libros por La } \\
\text { República y El } \\
\text { Comercio, cobro } \\
\text { mínimo por las } \\
\text { clases de cóm- } \\
\text { puto en media. } \\
\text { Aplicación del } \\
\text { reglamento de } \\
\text { disciplina para } \\
\text { el cumplimiento } \\
\text { de los horarios } \\
\text { de ingreso y } \\
\text { salida de los } \\
\text { alumnos. }\end{array}$ & ¿? & $\begin{array}{l}\text { Mensualidad } \\
\text { de } 120 \text { a } 150 \\
\text { soles, Apafa, } \\
\text { actividades y } \\
\text { apoyo de la } \\
\text { comunidad } \\
\text { Nikkei } \\
\text { y de la } \\
\text { comunidad } \\
\text { educativa. }\end{array}$ \\
\hline
\end{tabular}

Sin duda alguna, el concepto de la familia, signada por el manejo instrumental del PEI, que ve a los padres como un tema de apoyo económico, académico y afectivo. Hay una apreciación crítica desde los colegios acerca de la falta de interés de los mismos por el desarrollo cotidiano de sus hijos.

\footnotetext{
9 Teresa González de Fanning es un colegio piloto en educación de niños, jóvenes y adultos.
} 
Cuadro 6

\begin{tabular}{|c|c|c|c|c|c|}
\hline $\begin{array}{l}\text { Colegio: } \\
\text { dato }\end{array}$ & $\begin{array}{c}\text { Héroes de la } \\
\text { Breña }\end{array}$ & José María Arguedas & $\begin{array}{c}\text { Elías } \\
\text { Aguirre } \\
\text { y Casa } \\
\text { Abierta }\end{array}$ & $\begin{array}{c}\text { Teresa } \\
\text { González } \\
\text { de } \\
\text { Fanning }\end{array}$ & La Victoria \\
\hline $\begin{array}{l}\text { Papel de } \\
\text { los pa- } \\
\text { dres de } \\
\text { familia }\end{array}$ & $\begin{array}{l}\text { Poco respon- } \\
\text { sable y escasa } \\
\text { comunicación } \\
\text { con la institu- } \\
\text { ción educativa. } \\
\text { La mayoría no } \\
\text { toma en cuenta } \\
\text { el avance del } \\
\text { aprendizaje de } \\
\text { sus hijos. Poco } \\
\text { diálogo entre } \\
\text { padres e hijos y } \\
\text { escasa comuni- } \\
\text { cación afectiva. } \\
\text { No se propicia } \\
\text { la práctica de } \\
\text { valores en el } \\
\text { hogar. Poca } \\
\text { participación en } \\
\text { el quehacer de la } \\
\text { escuela. }\end{array}$ & $\begin{array}{l}\text { En lo político y } \\
\text { socio-económico hay } \\
\text { bajos recursos de los } \\
\text { padres de familia y no } \\
\text { financian los materia- } \\
\text { les de sus hijos. En lo } \\
\text { socio-cultural hay una } \\
\text { práctica distorsionada } \\
\text { de los valores en los } \\
\text { padres de familia. Los } \\
\text { alumnos provienen } \\
\text { de hogares consti- } \\
\text { tuidos donde ambos } \\
\text { padres toman deci- } \\
\text { siones. Los padres } \\
\text { tienen un concepto } \\
\text { claro de valores sien- } \\
\text { do los más conocidos } \\
\text { la honestidad, la soli- } \\
\text { daridad y el respeto. }\end{array}$ & $\begin{array}{l}\text { No son } \\
\text { tomados } \\
\text { en cuenta } \\
\text { dentro del } \\
\text { proyecto } \\
\text { educativo, } \\
\text { salvo por } \\
\text { los recursos } \\
\text { económicos. }\end{array}$ & & $\begin{array}{l}\text { Los padres } \\
\text { tienen interés } \\
\text { por la insti- } \\
\text { tución, cum- } \\
\text { plen con sus } \\
\text { obligaciones } \\
\text { económicas, } \\
\text { se comunican } \\
\text { estrechamente } \\
\text { con los docen- } \\
\text { tes. Muchos } \\
\text { de sus hogares } \\
\text { tienen deficien- } \\
\text { te constitución } \\
\text { por la emigra- } \\
\text { ción a Japón y } \\
\text { tienen econo- } \\
\text { mía no saneada } \\
\text { y dificultades } \\
\text { económicas. } \\
\text { La mayoría son } \\
\text { profesionales. }\end{array}$ \\
\hline
\end{tabular}

Cuadro $7^{10}$

\begin{tabular}{|l|l|l|l|l|l|}
\hline $\begin{array}{l}\text { Colegio: } \\
\text { dato }\end{array}$ & Héroes de la Breña & $\begin{array}{l}\text { José María } \\
\text { Arguedas }\end{array}$ & $\begin{array}{l}\text { Elías Aguirre y } \\
\text { Casa Abierta }\end{array}$ & $\begin{array}{l}\text { Teresa } \\
\text { Gonzáles de } \\
\text { Fanning }\end{array}$ & La Victoria \\
\hline $\begin{array}{l}\text { Oportu- } \\
\text { nidades }\end{array}$ & $\begin{array}{l}\text { Comunicación con } \\
\text { Educentro Red N. } \\
\text { 05. La práctica de } \\
\text { deportes, las fiestas } \\
\text { patronales, presen- } \\
\text { cia de artesanos } \\
\text { y de artistas. Un } \\
\text { Centro Educativo } \\
\text { Ocupacional. Opor- } \\
\text { tunidad de trabajo } \\
\text { para algunos alum- } \\
\text { nos. Radio Planeta } \\
\text { que es comunitaria. }\end{array}$ & $\begin{array}{l}\text { Apoyo de insti- } \\
\text { tuciones, parti- } \\
\text { cipación activa } \\
\text { de la comunidad. } \\
\text { Apoyo de pro- } \\
\text { fesionales y } \\
\text { practicantes de las } \\
\text { universidades e } \\
\text { institutos superio- } \\
\text { res. Organización } \\
\text { en comisiones } \\
\text { de vestido, } \\
\text { industria } \\
\text { alimentaria, } \\
\text { atención } \\
\text { infantil, } \\
\text { contabilidad } \\
\text { y } \\
\text { componsables }\end{array}$ & $\begin{array}{l}\text { Sujeta a la } \\
\text { Ley Ge- } \\
\text { neral de } \\
\text { Educación y } \\
\text { a las normas } \\
\text { de la Aso- } \\
\text { ciación Pe- } \\
\text { ruano Japo- } \\
\text { nesa como } \\
\text { entidad } \\
\text { rectora de la } \\
\text { comunidad } \\
\text { Nikkei. }\end{array}$ \\
\hline
\end{tabular}

10 Hay un conjunto de instituciones que retroalimentan la labor del colegio sin haber convenio alguno como Casa Abierta con sus servicios de biblioteca, ludoteca, videoteca, atención psicológica, talleres ocupacionales para mujeres, atención médica en la parroquia Virgen de Nazaret con su catequesis, campeonatos deportivos y otros. 
En este cuadro 7 aparecen dos rasgos interesantes desde el punto de vista del enfoque cultural, no porque las aspiraciones académicas no sean importantes, sino que por el tema de este estudio importa ver de qué manera es tomado el factor cultural. En el colegio La Victoria se hace palpable una línea de política cultural de la Asociación Peruano Japonesa y su incidencia en el colegio como espacio de valoración de esta cultura y de la peruana. El colegio Héroes de la Breña enfatiza valores sociales recurrentes hacia la identidad local del migrante andino, así, los deportes, las fiestas patronales, los artesanos y los artistas se hacen sentir como una oportunidad, a lo cual se suma el Centro de Educación Ocupacional y la participación en una radio local.

Así se presentan dos ejemplos que incorporan esta dimensión cultural como eje de sus oportunidades, lo que remite a algo muy profundo como es la identidad ancestral e histórica y no solamente alude a una identidad instrumental.

En el cuadro 8 se mencionan las fortalezas las cuales se direccionan al desarrollo académico e institucional. Cabe comparar algunos contrastes. Por ejemplo, en Héroes de la Breña se destaca que lo docentes estén titulados y que haya algunos alumnos desatacados y Elías Aguirre destaca el ejercicio de la puntualidad. ¿Son estos los valores más destacados por las condiciones en las que existen en cada uno de ellos? En el colegio José María Arguedas se destaca la importancia de la forma participativa en hacer el PEI de su comunidad educativa. En cambio, en el colegio Teresa González de Fanning y La Victoria enfatizan los procesos cognitivos y la configuración de actitudes y procesos educativos por los cuales pasan sus fortalezas. Solo el colegio Teresa González de Fanning habla de formar ciudadanas como una fortaleza. Los colegios ubicados en los asentamientos humanos tienen mayor debilidad en lograr una disciplina en cuanto a la puntualidad y este tema es importante porque implica la dedicación a las labores académicas, tanto por los alumnos como por los profesores. 


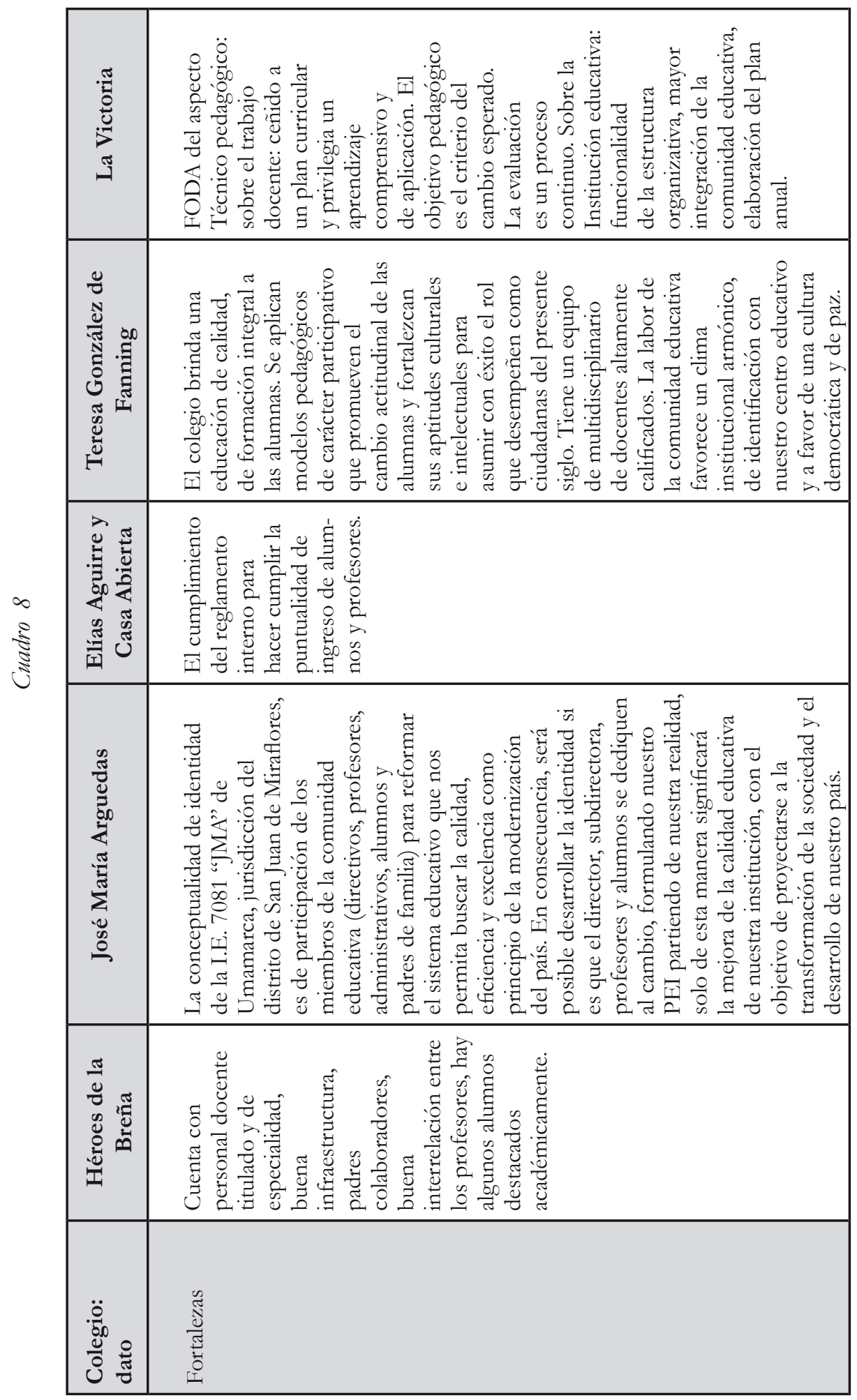


En cuanto a las debilidades — ver cuadro 9- se aprecia como denominador común la baja autoestima, dada las carencias económicas y falta de oportunidades de realización. Como parte de las debilidades es considerada la familia, la realidad deficiente en la calidad educativa; la realidad familiar vista como afectada por su "bajo nivel cultural", por su "poca preocupación por el proceso educativo de sus hijos". El colegio José María Arguedas asume falta de tutoría o de OBE, "débil planificación y organización institucional", parece ser que es muy conciente de la vulnerabilidad docente al no poder dedicarse a los alumnos de manera más integral, al no dedicarse a preparar mejor sus clases.

\section{Cuadro 9}

\begin{tabular}{|c|c|c|c|c|c|}
\hline $\begin{array}{l}\text { Colegio: } \\
\text { datos }\end{array}$ & $\begin{array}{c}\text { Héroes de } \\
\text { la Breña }\end{array}$ & José María Arguedas & $\begin{array}{c}\text { Elías } \\
\text { Aguirre y } \\
\text { Casa Abierta }\end{array}$ & $\begin{array}{c}\text { Teresa } \\
\text { González } \\
\text { de } \\
\text { Fanning }\end{array}$ & La victoria \\
\hline $\begin{array}{l}\text { Debilidades } \\
\text { internas }\end{array}$ & $\begin{array}{l}\text { Poca comu- } \\
\text { nicación con } \\
\text { los padres } \\
\text { de familia, } \\
\text { su bajo nivel } \\
\text { cultural y su } \\
\text { poca preocu- } \\
\text { pación por } \\
\text { el proceso } \\
\text { educativo de } \\
\text { sus hijos, los } \\
\text { que a su vez } \\
\text { tienen baja } \\
\text { autoestima. } \\
\text { Carencia de } \\
\text { una secre- } \\
\text { tía que los } \\
\text { apoye }\end{array}$ & $\begin{array}{l}\text { Baja autoestima y } \\
\text { conductas sociales in- } \\
\text { adecuadas; deficiente } \\
\text { rendimiento escolar por } \\
\text { la desintegración familiar, } \\
\text { desinterés de los padres; } \\
\text { carencia de ambientes } \\
\text { para ofrecer servicios } \\
\text { de OBE, de tutoría, de } \\
\text { escuela para padres; de- } \\
\text { bilidad en la planificación } \\
\text { y organización institucio- } \\
\text { nal; falta de apoyo de los } \\
\text { padres en las actividades, } \\
\text { tareas, faenas y otros. } \\
\text { Bajo nivel de conoci- } \\
\text { mientos culturales de los } \\
\text { docentes por los bajos } \\
\text { sueldos y excesos de tra- } \\
\text { bajos, por falta de tiempo } \\
\text { no preparan la diversi- } \\
\text { ficación del currículo. } \\
\text { Falta de preparación para } \\
\text { el desarrollo de la creati- } \\
\text { vidad y la reflexión en los } \\
\text { alumnos. }\end{array}$ & $\begin{array}{l}\text { Alto porcen- } \\
\text { taje de repi- } \\
\text { tencia escolar. } \\
\text { Bajos prome- } \\
\text { dios acadé- } \\
\text { micos. Alto } \\
\text { porcentaje } \\
\text { de abandono } \\
\text { escolar. Poca } \\
\text { participación } \\
\text { y colabora- } \\
\text { ción de los } \\
\text { padres de } \\
\text { familia. Falta } \\
\text { de seguridad. } \\
\text { Escado mate- } \\
\text { rial educativo. } \\
\text { Interrupción } \\
\text { de la jornada } \\
\text { laboral por } \\
\text { reuniones } \\
\text { intermedias. }\end{array}$ & & $\begin{array}{l}\text { Definir si- } \\
\text { tuación legal } \\
\text { del plantel, } \\
\text { reestructu- } \\
\text { ración de los } \\
\text { programas } \\
\text { curriculares, } \\
\text { capacitar } \\
\text { más a los } \\
\text { profesores } \\
\text { en nuevos } \\
\text { métodos y } \\
\text { contenidos. } \\
\text { Dotar de } \\
\text { mejores } \\
\text { materiales a } \\
\text { la sala de au- } \\
\text { diovisuales. }\end{array}$ \\
\hline
\end{tabular}

En el lema del colegio se ve reflejada la cultura de valores que es fundamental para ver cómo se integra la cultura propia en la cultura educativa. Pues en el caso de La Victoria, se precisa la importancia de la familia, lo cual es coherente con los valores japoneses tradicionales. Pero en los otros colegios se privilegia la disciplina y el trabajo como valoración importante dentro del lema, mientras que el honor y 
la virtud aparecen sobre todo en el colegio Teresa González de Fanning, que forma señoritas y ciudadanas.

Cuadro 10

\begin{tabular}{|l|l|l|l|l|l|}
\hline $\begin{array}{l}\text { Colegio: } \\
\text { datos }\end{array}$ & $\begin{array}{c}\text { Héroes } \\
\text { de la } \\
\text { Breña }\end{array}$ & $\begin{array}{l}\text { José María } \\
\text { Arguedas }\end{array}$ & $\begin{array}{c}\text { Elías Aguirre } \\
\text { y Casa } \\
\text { Abierta }\end{array}$ & $\begin{array}{c}\text { Teresa } \\
\text { González de } \\
\text { Fanning }\end{array}$ & La Victoria \\
\hline Lema & & $\begin{array}{l}\text { Honor y } \\
\text { trabajo, } \\
\text { disciplina y } \\
\text { acción. }\end{array}$ & $\begin{array}{l}\text { Disciplina, } \\
\text { superación y } \\
\text { trabajo. }\end{array}$ & $\begin{array}{l}\text { Ciencia, virtud } \\
\text { y honor. }\end{array}$ & $\begin{array}{l}\text { Hagamos de la } \\
\text { escuela un hogar } \\
\text { y de cada hogar } \\
\text { una escuela. }\end{array}$ \\
\hline
\end{tabular}

Los valores - cuadro 11- muestran una clara conciencia sobre la necesidad de enseñar los derechos y de la comprensión de la convivencia en democracia y sus valores como la puntualidad, una cultura educativa de éxito, promoción de comportamientos ciudadanos, promover un espíritu democrático. Contrasta el planteamiento de La Victoria donde más bien se refuerzan los valores tradicionales y la interculturalización partiendo de la familia y de manera complementaria, propicia la responsabilidad de los padres como primeros educadores. La Victoria hace explícitos sus valores de "Disciplina, trabajo, responsabilidad, puntualidad, respeto, solidaridad, lealtad y honradez," valores comunes a todos los colegios. 
Cuadro $11^{11}$

\begin{tabular}{|c|c|c|c|c|c|}
\hline $\begin{array}{l}\text { Colegio: } \\
\text { datos }\end{array}$ & $\begin{array}{l}\text { Héroes de la } \\
\text { Breña }\end{array}$ & $\begin{array}{c}\text { José María } \\
\text { Arguedas }\end{array}$ & $\begin{array}{c}\text { Elías Aguirre y } \\
\text { Casa Abierta }\end{array}$ & $\begin{array}{c}\text { Teresa } \\
\text { González } \\
\text { de } \\
\text { Fanning }\end{array}$ & La Victoria \\
\hline Valores & $\begin{array}{l}\text { Paz: asumir } \\
\text { normas de } \\
\text { convivencia y } \\
\text { hábitos sociales } \\
\text { que promuevan } \\
\text { un ambiente de } \\
\text { afecto, armo- } \\
\text { nía, libertad, } \\
\text { solidaridad, } \\
\text { compañerismo } \\
\text { y ayuda mutua. } \\
\text { Respeto: mues- } \\
\text { tra de actitud } \\
\text { de buena con- } \\
\text { ducta, hones- } \\
\text { tidad, sinceri- } \\
\text { dad, confianza, } \\
\text { comunicación } \\
\text { y tolerancia. } \\
\text { Responsabili- } \\
\text { dad: actuar con } \\
\text { puntualidad, } \\
\text { responsabi- } \\
\text { lidad en las } \\
\text { acciones, liber- } \\
\text { tar con respon- } \\
\text { sabilidad a los } \\
\text { derechos y a } \\
\text { las normas, or- } \\
\text { den e higiene. }\end{array}$ & & $\begin{array}{l}\text { Fomenta valores } \\
\text { de una cultura } \\
\text { educativa de éxi- } \\
\text { to permitiendo } \\
\text { comprender el } \\
\text { mundo y actuar } \\
\text { sobre su entor- } \\
\text { no respetando } \\
\text { su identidad. } \\
\text { Propicia las bue- } \\
\text { nas relaciones } \\
\text { humanas dentro } \\
\text { de la comunidad } \\
\text { educativa. Iden- } \\
\text { tifica al C.E. con } \\
\text { la problemática } \\
\text { del entorno. } \\
\text { Promover el } \\
\text { conocimiento } \\
\text { y comprensión } \\
\text { de su medio } \\
\text { natural y socio- } \\
\text { cultural. Promo- } \\
\text { ver el respeto } \\
\text { de los derechos } \\
\text { humanos y el } \\
\text { desarrollo de los } \\
\text { comportamien- } \\
\text { tos. }\end{array}$ & $\begin{array}{l}\text { Investi- } \\
\text { gación, } \\
\text { trabajo, } \\
\text { creatividad, } \\
\text { deporte, ac- } \\
\text { titud crítica } \\
\text { y reflexiva. } \\
\text { Espíritu de- } \\
\text { mocrático } \\
\text { y solidario. } \\
\text { Cultura de } \\
\text { paz. }\end{array}$ & $\begin{array}{l}\text { Disciplina, trabajo, } \\
\text { responsabilidad, } \\
\text { puntualidad, respeto, } \\
\text { solidaridad, lealtad y } \\
\text { honradez. Los valores } \\
\text { también se expresan } \\
\text { en algunos puntos del } \\
\text { ideario: su misión es } \\
\text { mantener y consoli- } \\
\text { dar los valores, cos- } \\
\text { tumbres, tradiciones e } \\
\text { idioma japonés como } \\
\text { proceso de intercultu- } \\
\text { ralización peruano-ja- } \\
\text { ponesa. Motiva a una } \\
\text { alta formación aca- } \\
\text { démica, al trabajo y a } \\
\text { la práctica del idioma } \\
\text { japonés. Se practican } \\
\text { las normas de corte- } \\
\text { sía y hábitos de res- } \\
\text { peto hacia sí mismo y } \\
\text { hacia los demás. Dar } \\
\text { a la familia el valor } \\
\text { que le corresponde } \\
\text { dentro de la labor } \\
\text { educativa propiciando } \\
\text { la responsalibilidad } \\
\text { de los padres como } \\
\text { primeros educadores. }\end{array}$ \\
\hline
\end{tabular}

\section{Cuadro 12}

\begin{tabular}{|c|c|c|c|}
\hline $\begin{array}{l}\text { Amenazas } \\
\text { externas }\end{array}$ & $\begin{array}{l}\text { En el entorno del co- } \\
\text { legio hay videojuegos, } \\
\text { hostales y lugares donde } \\
\text { expenden licores. Exis- } \\
\text { tencia de vicios como la } \\
\text { drogadicción y el pan- } \\
\text { dillaje, crisis de valores } \\
\text { y mal uso del Internet. } \\
\text { Ausencia de alianzas con } \\
\text { instituciones culturales. }\end{array}$ & $\begin{array}{l}\text { Guerra entre pandillas } \\
\text { de } 50 \text { chicos cada una y } \\
\text { violencia juvenil. Desin- } \\
\text { tegración familiar. Falta } \\
\text { de contenidos educativos } \\
\text { en la educación informal } \\
\text { como en los medios de } \\
\text { comunicación y exceso } \\
\text { de contenidos violentos } \\
\text { y pornográficos. }\end{array}$ & $\begin{array}{l}\text { Prolifera la delincuen- } \\
\text { cia y la prostitución }\end{array}$ \\
\hline
\end{tabular}

11 El colegio José María Ar,guedas no explicita sus valores aún en su PEI, pero señala los temas transversales, que contienen un carácter valorativo: convivencia, paz y ciudadanía; derechos humanos; interculturalidad; amor, familia, sexualidad; Medio ambiente; y equidad de género. 
Por último, el cuadro 12 nos ilustra del grave problema que se presenta por la violencia local producida por los mismos jóvenes del propio colegio y del propio barrio que integran sus propias pandillas con sus reglas de comportamiento social de mucho arraigo emocional, cultural y familiar. Los colegios culpan a los negocios que viven de los alumnos, entre ellos a los medios de comunicación por no controlar sus contenidos

¿Quiénes son y cómo son los alumnos de hoy, sobre todo en los asentamientos humanos caracterizados por su cultura migrante? Muchos de ellos son quienes viven las secuelas psicológicas del terrorismo. Así el informe de la CVR señala la necesidad de apoyo que requieren un conjunto de personas que han sido afectadas por la destrucción de sus vidas, para reconstruir sus vidas y sus vínculos familiares "es evidente que sus esfuerzos personales deben sumarse a formas de apoyo del Estado y del conjunto de la sociedad, sobre todo para atender al desafío de no prolongar en la socialización de sus hijos de hoy los sufrimientos y traumas a los que han sido expuestos" (CVR Secuelas psicosociales 2002: 197).

La violencia ha dejado a niñas y niños asustados, cohibidos que no pueden atender, concentrarse, retener lo que escuchan. Su proceso de aprendizaje resulta dañado. A veces parecen sin curiosidad ni interés por lo nuevo. Sus demandas emocionales y también materiales las orientan a los profesores y estos a su vez a las autoridades. Se incrementan la impotencia y la frustración, los profesores terminan desvalorizando su trabajo y función. La capacidad de saber y conocer fue especialmente blanco de ataques durante el tiempo de la violencia (CVR Secuelas psicosociales 2002: 255).

Quiero precisar una conclusión central en todo este análisis, salvo el colegio La Victoria, ninguno tiene una política cultural definida, incluso tomando en cuenta que este caso revalora las tradiciones japonesas y peruanas. Los otros colegios dan por descontado que deben ser peruanos, pero no revaloran las raíces andinas de su comunidad educativa, ni siquiera toman en cuenta sus valores comunitarios ni sus propias gestas para retomarlo en su modelo educativo. Así la matriz cultural andina presente en la autoconstrucción y el apoyo comunitario son asumidos como un asunto obligatorio, pero no como un valor. Es interesante ver cómo el énfasis puesto en los padres de familia como primeros educadores solo es enfocado por La Victoria, siendo los padres un factor fundamental vinculante en la transmisión de la cultura materna tanto andina como japonesa, los padres son tipificados como de baja cultura y los colegios se esmeran en realizar escuela para padres. Esto impide mirar con objetividad el conflicto cultural que hay detrás.

La interculturalidad supone una mirada política diferente, de carácter pluralista desde la cual "reinterpretar lo político, lo social, lo étnico, lo cultural y lo lingüístico que busca articular las diferentes sociedades étnicas dentro de un Estado determinado" (Luis Enrique López 2000: 181-2). Busca el encuentro explícito de tradiciones y discursos diferentes que incida en el aprendizaje de capacidades para el manejo de 
distintos lenguajes y códigos, impulsando una "educación intercultural para todos y no solo para los indígenas" (Ibíd: 183). No solo se trata de una educación bilingüe, si no de la cultura en su totalidad, donde existe la convivencia y el intercambio cultural continuo como mecanismo de adaptación al medio. Por ello es necesario hacer evidente el conflicto cultural para que pueda ser llevado al diálogo de manera explícita.

Se trata de revertir la negación hacia el otro y de proponer reconocer a ese otro su identidad colectiva que también nos incluye a nosotros y para ello es requisito desarrollar una "ciudadanía moderna... y extendida" (Calderón et al. 1994: 61).

A pesar de la difundida percepción de lo que es la identidad mestiza como una identidad de "todas las sangres", esta no elimina el conflicto ni la presencia y dinámica de costumbres de los sustratos socioculturales, quienes vivencian una dinámica que moviliza a sus individuos y a sus colectividades de un extremo a otro en el continuum entre tradición y modernidad. Tradición que les es abiertamente negada en los espacios públicos nacionales — como el uso del idioma vernácula en las ciudades_-, además, la modernidad les es estructuralmente negada debido al alto costo de la educación; "solo el acervo cultural del sí mismo, histórico y no instrumental, es el núcleo básico para desde allí reinterpretar y adecuar las ideologías modernizadoras [...] abriendo un diálogo fructífero (Ibíd: 84) siempre se incorpora la modernidad de manera sincrética" (Ibíd: 86).

La problemática cultural nutre la reflexión sobre la educación y sobre la ciudadanía y ambas a la vez están complementadas por un tercer aspecto, por los medios de comunicación. La escuela, la ciudadanía y la TV han contribuido a gestar una cultura de masas:

Las masas pasan directamente de su fase folklórica y oral a participar de una vida social donde se requiere manejar códigos absolutamente distintos: racionalidad burocrática, racionalidad técnica y mentalidad abstracta. La velocidad de estos cambios lleva a la coexistencia, bajo múltiples gradaciones de ambos extremos (Ibíd: 89).

Los medios permiten la coexistencia del cosmopolitanismo y del localismo, es decir la coexistencia de tiempos y velocidades distintas se contrastan constantemente los mensajes recibidos y el ambiente cultural local. La modernidad significa "un tiempo nuevo que contiene muchos tiempos" (Ibíd:90) produciendo una "cierta hibridez cultural" (Ibíd).

La concentración en el aula se tensa con la fuerza dispersora de los multimedia. El mestizaje trasciende su rango étnico y se convierte en un evento cotidiano y para todos los actores: no hay identidades que resistan en estado puro más de unas horas ante la fuerza de estímulos que provienen de todos los rincones del planeta. La estética del collage y del pastiche, tan cara a la sensibilidad posmoderna, no es casual: constituye una metáfora de esta condición de continua recomposición de sensibilidades y mensajes culturales (Ibíd). 
Es central hablar de los medios y de la importancia del desarrollo de la industria cultural como tercer elemento: escuela, ciudadanía y medios; para lograr un desarrollo con identidad, es decir un desarrollo desde dentro, desde el sí mismo individual y colectivo. Los medios pueden ser útiles para promover la participación de la ciudadanía de manera indistinta para que informe libremente lo que ocurre en su localidad, pueden ayudar a prevenir grandes males y pueden ayudar a coordinar acciones conjuntas. Pueden contribuir a gestar una cultura interactiva a gran escala, dando a conocer demandas sociales; pueden descentrar los mensajes para ayudar a democratizar la región permitiendo la participación de grupos segregados. El desarrollo y consolidación de la industria cultural endógena es fundamental para garantizar el acceso al conocimiento y a la información, lo cual debe complementarse con la formación de una ciudadanía extendida a través de la educación formal y comunitaria; y, con el desarrollo de una política deliberada de promoción e integración que ayude a revertir la discriminación cultural, la exclusión económica y la marginación de la participación política.

Para finalizar esta ponencia quiero comentar las entrevistas a los y las jóvenes alumnas de los colegios.

La matriz andina se ve reflejada en un conjunto de aspectos y el primero de ellos es esa tradicional manera de configurar las familias extensas y este rasgo es más notorio en los colegios de los asentamientos humanos. La presencia del trabajo de autoempleo dentro del hogar con el padre y el apoyo de los hijos, la conciencia del lugar de procedencia y las celebraciones patronales en la cancha de fulbito de la plaza del Asentamiento Humano Huanta, por ejemplo. Allí se festeja el Maynai por tres días. También existe el castigo físico y psicológico dentro de la familia creando en los hijos temor, sentimiento que se ve acrecentado por sus relaciones conflictivas dentro de la escuela, sobre todo si el alumno o alumna es migrante. Se ve como una de las tradiciones más grandes, las tradiciones religiosas católicas que son transmitidas de padres a hijos. El trabajo como una de las dimensiones educativas, la formación laboral aparece en todos los colegios y forma parte de los valores andinos.

El entorno urbano de los colegios de los asentamientos humanos es muy pobre, los padres de familia son informales, pequeños comerciantes, transportistas, obreros, empleadas domésticas. Muchos de ellos desplazados por la violencia senderista, muchos son quechua hablantes. La mayoría de los alumnos trabajan y estudian.

En cuanto a la instrucción que se imparte en el colegio, sobre todo en las áreas periféricas, hay un sentimiento de insatisfacción respecto a la poca dedicación de los profesores, pero esto también se debe a la pobreza del profesor que tiene otros trabajos y llega cansado a enseñar.

Sobre el entorno comunitario, todos los colegios expresaron su malestar a la violencia y delincuencia vivida en el entorno del colegio. Bajos estándares de salubridad. El consumo de drogas, la presencia de la prostitución y de las pandillas. Se puede ver que algunos colegios han sido beneficiados por terceros actores como la Asociación Peruano Japonesa o en el caso del Teresa González de Fanning que tiene el apoyo de un conjunto de instituciones sociales como el Club de Leones, El Rotary, además el Municipio y del propio Ministerio de Educación. En otros casos a ONG, 
parroquias, asociaciones de vecinos y diversas manifestaciones comunitarias como la cercanía a dos radios.

Tampoco hay que olvidar el carácter consumista de los jóvenes de hoy, el cual está promovido por la cultura de masas. Conviven muchos estilos de consumo según las biografías personales y las socializaciones; los ciudadanos son consumidores y el consumidor se convierte en un hermeneuta que selecciona, reconoce, se apropia y traduce... (Ibíd: 92). Los propios jóvenes entrevistados manifiestan ser consumidores del conjunto de ofertas de diversión, de música, de programas y películas ofrecidas por los medios.

Esta primera aproximación ha buscado resaltar cuáles son los enfoques culturales involucrados. Se puede ver que en la gran masa de familias, el gran peso cultural va por el lado andino sobre todo en los asentamientos humanos. En el caso de La Victoria hay mucho énfasis en la cultura japonesa y en la eficiencia de su cultura organizacional; ser Nikkei es una identidad de orgullo que se socializa y promueve. $\mathrm{Mu}$ chos de los padres esperan darle educación solo hasta quinto de media, muchos hijos tienen a sus padres en Japón, muchos alumnos esperan migrar al Japón para trabajar.

Tanto el colegio La Victoria como el Teresa González de Fanning tienen alumnos y alumnas que provienen de familias más pequeñas, son colegios de procedencia más urbana. En cuanto al Teresa González de Fanning, parece haber logrado un espíritu gregario de identificación al colegio pesar de sus métodos represivos respecto del uso y cumplimiento, al pie de la letra, del reglamento acerca del uniforme y de cómo se debe llevar. Sin embargo, es un colegio de gran prestigio a nivel nacional y los padres llevan a sus hijas a cursar la media solo entre niñas para evitar el contacto con chicos. Se valora la feminidad y maternidad. Muchas aspiran a ingresar a la universidad, cuestión que hace la diferencia con los otros colegios, expresan una preocupación por participar en la política como representantes en el gobierno, es un colegio que les da seguridad y autoestima, involucrado en una identidad urbana criolla.

Sin embargo, es de notar que en todos los colegios hay presencia andina, en unos predomina fuertemente esto; de modo distinto, en el Peruano Japonés hay un predominio de la cultura japonesa y respeto por la peruana, y en el Teresa González de Fanning está totalmente subsumida, a pesar que la diversidad cultural de sus alumnas.

Aunque esta es una investigación que recién se inicia, este campo de estudio promete mucho para el conocimiento de los conflictos culturales en el encuentro y redefinición de matrices culturales criollas y andinas y sus redefiniciones en nuevas identidades que transitan por continuos de tradición y modernidad. Así, nos encontramos ante la necesidad de reflexionar desde la realidad sociocultural y desde la escuela cuál es el horizonte y cuáles son las acciones que permitirán dibujar en esta segunda modernidad, las nuevas ciudadanías interculturales, la nueva educación intercultural y los nuevos medios interculturales.

Será posible proyectar una matriz cultural que no aspire a "ser otro" a negar su ser andino para llegar a ser culturalmente exitoso. Se necesita reenfocar el mestizaje hacia nuevas formas de ser que dejen de lado el monoculturalismo criollo y amplíen su rango a la inclusión de ese otro andino, que necesita de la educación. Como siste- 
ma de inclusión dentro de la escuela, en la comunidad y en los medios. Llegar a ser interculturales es un desafío profundo y radical. Forma parte de esta segunda modernidad, más participativa y diversa culturalmente.

¿Será posible que haya porosidades entre los representantes políticos, que haya entre ellos y en la sociedad civil, así como en el entorno educativo y sus funcionarios, mayor sensibilidad a la interculturalidad? ¿Podrá haber una política cultural que parta de reconocer los modelos estéticos y los valores andinos como válidos para ser peruano exitoso? ¿Podrá aceptarse el quechua como instrumento de comunicación oficial?

¿Cuál es el papel de la escuela, de los medios y de la ciudadanía en la preparación de este terreno intercultural?

\section{BIBLIOGRAFÍA}

BECK, Ulrich

1998 ¿Qué es la globalización? Paidos. España.

CALDERON, HOPENHYN y OTTONE

1996 Esa modernidad esquiva, Desarrollo, ciudadanía y cultura en América Latinay el Caribe. Unesco y nueva sociedad.

CONTRERAS, Carlos

1996 Maestros, Mistis y campesinos en el Perú rural del siglo XX. Lima: IEP, (Documento de Trabajo, 80. Serie Historia, 16).

LOPEZ, Luis Enrique

2000 "Interculturalidad y educación en América Latina", en Educación primaria al final de la década, pp 179-195. Tarea. Lima-Perú.

LOPEZ, Sinesio

2000 "Democracia y participación indígena. El caso peruano y aportes a la discusión", en Las sociedades interculturales: un desafío para el siglo XXI, cuarta parte. FLACSO.

COMISIÓN DE LA VERDAD Y RECONCILIACIÓN

2002 Tercera Parte: Secuelas de la violencia. Capítulo 1: Las secuelas psicosociales, en: Informe final de la $C V \mathrm{R}$. 